\title{
Excitatory and inhibitory contributions to local field potentials in human and monkey
}

\author{
Bartosz Teleńczuk*, Alain Destexhe \\ From Twenty Second Annual Computational Neuroscience Meeting: CNS*2013 \\ Paris, France. 13-18 July 2013
}

Local field potentials (LFPs) are a common measure of the neuronal population activity. However, their origins are not yet fully understood. A recent in vitro study has shown that even single spikes emitted by an interneuron can trigger detectable unitary field potentials in extracellular medium [1]. Their contributions can be additionally amplified due to strong spatial correlations in interneuronal firing [2]. Nevertheless, inhibitory activity in vivo is strongly correlated with the excitatory potentials leading to effective cancellations of generated field potentials. As a result, the unitary field potentials induced by interneuronal spikes can not be separated from background activity. Here, we describe a technique that allows to disambiguate the excitatory and inhibitory contributions.

We study the contribution of excitatory and inhibitory neurons in awake and sleeping brain of human and monkey. The experimental data were recorded intracortically in patients accepted for the surgical treatment of epileptic foci. We discriminated 82 single units over a electrode grid of 92 electrodes (covering an area of $4 \mathrm{~mm} \times 4 \mathrm{~mm}$ ) together with accompanying local field potentials. We compared the results with LPFs and spikes recorded from electrode arrays of the same geometry implanted in motor cortex of macaque monkeys [3]. For both datasets, we determined the field potential components related to spikes of inhibitory neurons by means of spike-triggered average (STA) and covariance (STC) methods [4].

First, we determined the spatial reach of the spikeinduced field by means of spike-triggered average analysis. We found that the potentials triggered by putative interneurons propagate across the electrode grid at velocity higher than the field of putative pyramidal neurons

\footnotetext{
* Correspondence: telenczb@biologie.hu-berlin.de Unité de Neurosciences, Information \& Complexité, Centre National de la Recherche Scientifique, 91198 Gif-sur-Yvette, France
}

(propagation velocity: $0.5 \mathrm{~m} / \mathrm{s}$ and $0.3 \mathrm{~m} / \mathrm{s}$, respectively). In addition, the spike-triggered covariance analysis revealed gamma-band components in the local field potentials of interneurons but not pyramidal neurons. These high-frequency components are most likely related to the oscillations generated within a local network. To test this hypothesis, we simulate a network of simplified neurons that manifest gamma-band synchronization. Next, we apply the spike-triggered analysis to the field potentials calculated as a local average of the membrane potentials. The results of the simulations are compared to the experimental data.

We demonstrate that spike triggered covariance allows to separate components that are not accessible to standard techniques due to cancellations of the field produced by inhibitory and excitatory potentials. The application of this technique to the activities recorded in interneurons revealed previously unidentified components of local field potentials. Computer simulations suggest that these components are related to nonlinear interactions within the networks of inhibitory and excitatory neurons. Interestingly, we have not found such gamma-band components in the LFPs associated with excitatory neurons. Overall, our results point to essentially different relations between LFPs and spikes of excitatory and inhibitory neurons. We propose that this difference may provide a new electrophysiological criterion for the identification of interneurons.

\section{Acknowledgements}

Work supported by the CNRS and the European Community (Brainscales project, FP7-269921).

Published: 8 July 2013

\section{References}

1. Bazelot M, Dinocourt C, Cohen I, Miles R: Unitary inhibitory field potentials in the CA3 region of rat hippocampus. J Physiol (Lond) 2010, 588(Pt 12):2077-2090.

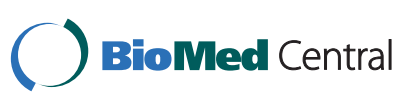

(c) 2013 Teleńczuk and Destexhe; licensee BioMed Central Ltd. This is an Open Access article distributed under the terms of the Creative Commons Attribution License (http://creativecommons.org/licenses/by/2.0), which permits unrestricted use, distribution, and reproduction in any medium, provided the original work is properly cited. 
2. Peyrache A, Dehghani N, Eskandar EN, Madsen JR, Anderson WS,

Donoghue JA, Hochberg LR, Halgren E, Cash SS, Destexhe A:

Spatiotemporal dynamics of neocortical excitation and inhibition during human sleep. Proc Natl Acad Sci USA 2012, 109:1731-1736.

3. Saleh M, Takahashi K, Hatsopoulos NG: Encoding of coordinated reach and grasp trajectories in primary motor cortex. J Neurosci 2012, 32:1220-1232

4. Estebanez L, El Boustani S, Destexhe A, Shulz DE: Correlated input reveals coexisting coding schemes in a sensory cortex. Nat Neurosci 2012, 15:1691-1699.

doi:10.1186/1471-2202-14-S1-P107

Cite this article as: Teleńczuk and Destexhe: Excitatory and inhibitory contributions to local field potentials in human and monkey. $B M C$

Neuroscience 2013 14(Suppl 1):P107.

Submit your next manuscript to BioMed Central and take full advantage of:

- Convenient online submission

- Thorough peer review

- No space constraints or color figure charges

- Immediate publication on acceptance

- Inclusion in PubMed, CAS, Scopus and Google Scholar

- Research which is freely available for redistribution

Submit your manuscript at www.biomedcentral.com/submit 